\title{
STRATEGI PEMASARAN LEMBAGA PENDIDIKAN DI SEKOLAH MI AL AMIN M 06 DI DESA TUNGGUL KECAMATAN PACIRAN KABUPATEN LAMONGAN
}

\section{Feri Uliya Candra}

Fakultas ekonomi dan bisnis islam Universitas islam Negeri sunan ampel Surbaya Email: feriuliya1402@gmail.com

\begin{tabular}{|c|c|}
\hline & \\
\hline & \multirow{11}{*}{$\begin{array}{l}\text { MI Al Amin M } 06 \text { Tunggul merupakan sekolah yang berlatar belakang } \\
\text { pesantren, sekolah ini berada di naungan yayasan pondok pesantren al } \\
\text { amin sekolah MI Al Amin M } 06 \text { mengalami penurunan jumlah siswanya } \\
\text { tiga tahun karena faktor persaingan. peneitian ini bertujuan untuk } \\
\text { menentukan strategi pemasaran lembaga pendidikan di MI Al Amin M } 06 \\
\text { Sekolah di desa Tunggul Paciran. Model penelitian ini menggunakan } \\
\text { pendekatan kualitatif dengan teknik data pengumpulannya yaitu observasi, } \\
\text { wawancara dan dokumentasi. Dari hasil penelitian yang srategis dilakukan } \\
\text { oleh MI Al Amin 06 tunggul yaitu dengan mengimplementasikan } \\
\text { pemasaran eksternal, internal pemasaran, pemasaran interaktif. Alat yang } \\
\text { digunakan melakukan strategi pemasaran yaitu dengan menerapkan } \\
\text { kualitas kerja guru, promosi kegatan pemasaran dilakukan di sekolah MI } \\
\text { Al Amin M 06 Tunggul yaitu dengan membuat, pamflet, Brosur serta } \\
\text { dilakukan melalui media sosial. }\end{array}$} \\
\hline & \\
\hline & \\
\hline & \\
\hline & \\
\hline & \\
\hline & \\
\hline & \\
\hline & \\
\hline & \\
\hline & \\
\hline
\end{tabular}

\begin{abstract}
MI Al Amin M O6 Tunggul is a school with a boarding school background, this school is in the auspices of the foundation of pondok pesantren al amin school MI Al Amin M 06 experienced a decrease in the number of students three years due to competition factors. This research aims to determine the marketing strategy of educational institutions at MI Al Amin M 06 School in The Village of Tunggul Paciran. This research model uses a qualitative approach with data collection techniques, strategic research conducted by MI Al Amin 06 stump, namely by implementing external marketing, internal marketing, interactive marketing. The tools used to carry out marketing strategies are by applying the quality of teacher work, marketing promotion is carried out at MI Al Amin M 06 Tunggul school, namely by making, pamphlets, brochures and done through social media.
\end{abstract} Keywords: $\quad$ namely observation, interview and documentation. From the results of marketing strategy, educational institutions, marketing marketing

\section{Pendahuluan}

Strategi pemasaran merupakan cara memenangkan keunggulan bersaing yang berkesinambungan baik itu untuk perusahaan yang memproduksi barang atau jasa. Strategi pemasaran dapat dilihat sebagai salah satu dasar yang dapat dipakai dalam penyusunan perencanaan secara menyeluruh. Menurut
Marrus dalam (Umar, 2001) strategi pemasaran didefisinikan sebagai proses penentuan rencana para pemimpin puncak dengan fokus pada tujuan jangka panjang organisasi, disertai penyusunan suatu cara untuk upaya bagaimana tujuan tersebut dapat dicapai. Strategi didefinisikan secara khusus sebagai tindakan yang bersifat incremental 
(senantiasa meningkatkan) dan terus-menerus, serta dilakukan berdasarkan sudut pandang tentang apa yang diharapkan oleh para pelanggan di masa depan.

Menurut (Tjiptono, 2019) strategi pemasaran yaitu rencana untuk menjabarkan ekspektasi perusahaan yang berdampak berbagai aktivitas atau program pemasaran terhadap permintaan produk atau ini produk di pasar sasaran tertentu. Program pemasaran meliputi tindakan pemasran yang mempengaruhi permintaan terhadap suatu barang atau jasa, diantaranya dalam mengubah hargai, memodifikasi kampanye iklan, merancangi, promosi khususi, menentukan pilihan saluran distribusi, dan sebagainya. Berdasarkan penelitian yang saya lakukan bahwa dalam suatu lembaga pendidikan untuk terus menawarkan sesuatu yang berbeda dari tahun-tahun sebelumnya, penawaran yang diberikan oleh pesaing seperti, pelayanan yang memuaskan, adanya produk unggulan dan kinerja guru yang berkualitas (Kamayuda, 2016). Sekolah yaitu organisasi yang bergerak dalam bidang jasa Pendidikan (Wijaya, 2008), maka dari itu dalam menyelenggarakan pendidkan pengelolah sekolah harus dapat melakukan dan menyusun strategi pemasaran dalam memasarkan sekolahannya. Tujuan dari pemasaran sekolahan adalah untuk saling memberikan informasi kepada masyarakat tentang produk dan jasa pendidikan antar satu sekolah dengan sekolahan yang lainnya (Putri, 2021), karena sekolah yang berkualitas merupakan sebuah impian bagi semua wali peserta didik dan seluruh elemen masyarakat untuk menciptakan sumberdaya manusia (SDM) yang berkualitas yang mampu memberikan dampak berubahan yang besar serta baik bagi bangsa dan negara, karena sekolah yang berkualitas tinggi merupakan sekolah yang memuaskan pelanggan (Amin, 2018) .

Pendidikan Agama Islam bersifat keagaamaan yang luas, sekolah Madrasah Ibtidaiyah Al Amin M 06 merupakan sekolah yang bersetatus swasta yang terakkreditasi A ini di bawah naungan Yayasan Al Amin, Dikdasmen dan Kementrian Agama. Dimana nama Yayasan Al Amin diambil dari seorang Kyai sekaligus pendidiri yayasan $\mathrm{Al}$ Amin dan pahlawan kemerdekaan yaitu K.H. Moh. Amin Musthofa yang sangat berjasa dalam kemerdekaan Indonesia terutamanya di kawasan pantura Lamongan, oleh karena itu sekolah MI Al Amin M 06 adalah sekolah yang berbasis pesantren yang mengusung mata pelajaran umum dan agama secara seimbang. Dengan perkembangan zaman semakin maju dan pesat oleh karena itu pendidikan agama sangat di butuhkan di era modern saat ini untuk meningkatkan pendidikan dan akhlak yang baik bagi anakanak. Sekolah yang berlatar bekalang agama islam dan pesantren ini mempunyai jumlah siswa yang sedikit menurun tiap tahunnya.

Tabel 1

Data Jumlah peserta didik MI Al Amin M 06.

\begin{tabular}{ll}
\hline Tahun Pelajaran & Jumlah \\
\hline $2018 / 2019$ & 193 \\
\hline $2019 / 2020$ & 178 \\
\hline $2020 / 2021$ & 172 \\
\hline
\end{tabular}

Sumber : data siswa diolah 2020

Jumlah siswa sekolah Mi Al Amin M 06 ini tiap tahunnya sedikit menurun karena beberapa faktor persaingan antar sekolahan dalam menarik peserta didik. Berdasarkan permasalahan yang ada maka penelitian ini bertujuan dapat mengetahui setrategi pemasaran lembaga pendidikan di sekolah MI Al Amin M 06.

\section{Metode Penelitian}

Penelitan ini menggunakan jenis penelitian pendekatan kualitatif. Penelitian kualitatif menurut (Nasution, 2017) merupakan tradisi dalam ilmu pengetahuan sosial secara ifundamental bergantung pada 
pengamatan manusia dalam kaasannya sendiri dan berhubungan dengan orang tersebut dalam bahasannya dan peristilahannyai. Penelitian kualitatif memiliki ciri atau karakteristik yang dapat membedakan dengan penelitian jenis lainnya.

Hasil riset metode kualitatif bisa berupa teks lisan (Anggito \& Setiawan, 2018). Lisan dan bentuk tingkah laku yang bisa diobservasi dari data deskriptif. Hasil penelitian deskriptif memuat data yang berisi informasi yang menjelaskan deskripsi umum dari data berupa kutipan yang bersumber dari hasil wawancara, manuskrip dan dokumen.

Fokus penelitian ini adalah membahas strategi pemasaran lembaga pendidikan di sekolah MI AL Amin M 06 Tunggul, lokasi yang dijadikan penelitian yaitu sekolah MI Al Amin M 06 Tunggul Kecamatan Paciran Kabupaten Lamongan yang berada dalam naungan yayasan Al Amin dan Majelis Dikdasmen. Data primer dilakukan melalui tahap pengamatan dan metode wawancara dengan kepala madrasah dan tata usaha sebagaimana yang berperan sebagai perancang dalam strategi pemasaran pendidikan di sekolah MI Al Amin M 06. Sumber data skunder melalui dokumen sekolah berupa brosur, pamflet, dan data sekolah MI AL Amin M 06 Tunggul. Teknik pengumpulan data menggunakan metode observasi, wawancara dan dokumentasi.

\section{Hasil dan Pembahasan}

Sekolah MI Al Amin M 06 melakukan strategi pemasaran lembaga pendidikan meliputi :

Pemasaran Internal (AZ’MI, 2013), pemasaran internal merupakan salah satu tugas yang dilakukan oleh sekolah dalam melatih dan memotivasi kinerja guru, tujuan dari pemberian pelatihan ini adalah agar meningkatkan kualitas sumber daya manusia dalam sistem pendidik serta mengembangka skill yang dimiliki oleh guru terutama guru kelas atau wali kelas. MI AL Amin M 06 memotivasi guru dengan mendorong dan memberikan pelatihan agar guru dapat bekerja dengan hati, bekerja dengan ikhlas, bekerja dengan disiplin dan tepat waktu seta mengemban amanat dengan baik sebagai pendidik, pelatihan yag diberikan kepada guru adalah pengembangan kurikulum serta pelatihan pengajaran.

Pemasaran Eksternal (AZ’MI, 2013), pemasaran eksternal merupakan pemasaran yang dilakukan guna memberikan berita dan informasi mengenai ruang lingkup lembaga pendidikan. Sekolah mempunyai tugas yaitu menentukan harga, mempromosikan lewat brosur, pamflet, serta media sosial dan menyiapkan program pendidikan yang memenuhi standar pendidikan. Sekolah MI Al Amin M 06 menawarkan program pembelajaran secara umum dan agama sesuai dengan kuriulum 2013, di sekolah MI Al Amin tenaga kependidikannya rata-rata sudah bersertifikasi dan sudah memenuhi standar sebagai pendidik, seta di sekolah MI AL Amin M 06 juga sudah dilengkapi dengan berbagai fasilitas seperti Lab komputer, Lapangan Futsal, Lapangan Voly, Transportasi siswa antar jemput dan ruangan kelas yang sudah memenuhi standar akreditasi. Untuk biaya siswa miskin/yatim gratis semua seragam sekolah dan biaya pendidikan.

Pemasaran interaktif, (Aryanti, 2020) pemasaran interaktif dilakukan untuk menjalin hubungan yang baik serta harmonis dengan masyarakat dan wali peserta didik, serta ketrampilan dan keramahan karyawan untuk memuaskan para wali peserta didik dalam melakukan administrasi sekolah. Sekolah MI Al Amin M 06 melakukan pelayanan bantuan bagi para siswa yang kurang mampu dengan adanya bantuan dari pemerintah seperti : BOS (Bantuan Operasioanal Sekolah), PIP (Program Indonesia Pintar) serta dari lembaga seperti bantual Siswa miskin, Siswa kurang mampu, dan siswa yatim maupun piatu.

\section{Kesimpulan}


Strategi pemasaran sekolah $\mathrm{MI} \mathrm{Al}$ Amin M 06 ada tiga yaitu pemasaran Internal dengan memperikan pelatihan-pelatihan dan memotivasi kinerja guru seperti pengembangan kurikulum dan pelatihan sebelum mengajar atau tatap muka. Pemasaran eksternal, kegiatan yang dilakukan di sekolah MI Al Amin M 06 yaitu program pembelajaran yang umum memnggunakan kurikulum 2013 serta sumber daya manusia yang cukup memadahi sebagai pengajar dan berbagai fasilitas-fasilitas yang di sediakan serta mempromosikan lembaga melalui brosur, pamflet dan media social. Pemasaran Interaktif, memberikan pelayanan kepada pelanggan jasa atau wali peserta didik dengan bantuan kepada siswa yang kurang mampu berupa bantuan dari pemerintah berupa BOS dan PIP serta dari lembaga sendiri untuk siswa kurang mampu, siswa miskin dan yatim piatu.

\section{Bibliografi}

Amin, S. (2018). Strategi Peningtkatan Kualitas Pelayanan Akademik Pada Sekolah Tinggi. Wahana Akademika: Jurnal Studi Islam Dan Sosial, 4(2), 193-202.Google Scholar

Anggito, A., \& Setiawan, J. (2018). Metodologi penelitian kualitatif. CV Jejak (Jejak Publisher). Google Scholar

Aryanti, Y. (2020). Pengaruh Pemasaran Interaktif Terhadap Kesadaran Merek Dan Minat Beli Konsumen Batik Tulis Ciwaringin Di Kota Cirebon. Universitas Islam Sultan Agung
Semarang. Google Scholar

AZ'MI, Y. U. (2013). Analisis Segitiga Pemasaran Jasa (Pemasaran Internal, Pemasaran Eksternal Dan Pemasaran Interaktif) Di Perpustakaan Universitas Airlangga. Universitas Airlangga. Google Scholar

Kamayuda, D. M. D. (2016). Perencanaan Strategi Bersaing Sekolah Dalam Meningkatkan Jumlah Peserta Didik Baru Di Salah Satu Sekolah Swasta Salatiga 1. Kelola: Jurnal Manajemen Pendidikan, 3(1), 15-29. Google Scholar

Nasution, L. M. (2017). Statistik deskriptif. Hikmah, 14(1), 49-55. Google Scholar

Putri, A. L. (2021). Strategi Komunikasi Pemasaran CV. AbankIrenk Yogyakarta Dalam Meningkatkan Penjualan Dimasa Pandemi Covid-19. Jurnal Ilmiah Komunikasi Makna, 9(2), 63-72. Google Scholar

Tjiptono, F. (2019). Strategi pemasaran. Google Scholar

Umar, H. (2001). Strategic management in action. Gramedia Pustaka Utama. Google Scholar

Wijaya, D. (2008). Implementasi Manajemen Mutu Terpadu dalam Penyelenggaraan Pendidikan di Sekolah. Jurnal Pendidikan Penabur, 10(7), 84-94 Google Scholar.

\section{Copyright holder :}

Feri Uliya Candra (2020).

First publication right :

Action Research Literate

This article is licensed under:

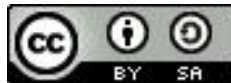

